Journal of Computer Science 8 (4): 474-481, 2012

ISSN 1549-3636

(C) 2012 Science Publications

\title{
Flexible Topology Migration in Optical Cross Add and Drop Multiplexer in Metropolitan Ring Network
}

\author{
${ }^{1,2}$ Mohammad Syuhaimi Ab-Rahman \\ ${ }^{1}$ Department of Electrical, \\ Faculty of Engineering and Built Environmental, \\ Spectrum Technology Reseach Group (SPECTECH), \\ Electronics and System Engineering, \\ ${ }^{2}$ Institute of Space Science (ANGKASA), \\ University Kebangsaan Malaysia, \\ 43600 UKM Bangi, Selangor, Malaysia
}

\begin{abstract}
Problem statement: Optical Cross Add and Drop Multiplexer (OXADM) is a recently invented optical networks device. Approach: A design with a purpose to combine the operational concepts of Optical Add-Drop Multiplexer (OADM) and Optical Cross Connect (OXC) has been developed. It is developed by studying the drawbacks in existing devices and with some excellence features added. OXADM is introduced to increase the survivability in the ring network. With the 'Accumulation' feature and ' $U$ ' turn reflection enable the multiplex, linear and ring protection scheme activated to ensure the signal arrives at the customer although breakdown occurs in the line and optical node. Beside that with the new features, the topology migration can also be done without the restructuring process due to randomly growth of new nodes. Results: The result shows that; network performance is similar without need a modification on components. Conclusion: Output power and BER performance at different node in ring and mesh optical network are shown to show the achievement of objective.
\end{abstract}

Key words: OXADM, migration, ring network, mesh network, BER

\section{INTRODUCTION}

In general, there are two types of optical node that used in present optical network where it depends on what type of topology that is implemented. OXC-based optical node is selected as a node distribution in the mesh network while OADM-based optical node is suitable for use in ring topology network (Tsushima et al. 1998). The selection of types of nodes depends on several factors such as signal movement format, its main function and also the security scheme used. Security scheme for node protection of ring topology is dedicated and shared protection. In addition, OADM nodes meet these security requirements by providing a mechanism for linear protection and ring protection. For node of mesh topology, the required security formats are dedication protection and dual homing (Tsushima et al. 1998). Thus the optical node based on OXC offers a linear protection and multiplex protection (OXN features) or called accumulation of signals on a single-pass' as a safety feature. So, it can be concluded that both types of nodes offers security features that differ according to node connection scheme where it called as a topology. If both functions are combined in a single architecture, the application of this hybrid device can be expanded as well as flexible features also can be enhanced. Nowadays, a number of issues were raised relating to the problems at dramatically increase in the number of users, followed by the high demand for new functions in communication systems. Demand for these new functions and additional bandwidth is solved by applying WDM technology into existing communication systems, thus turn it into transparent high data capacity with the introduction of carriers in the form of signal wavelength (Ab-Rahman and Moghaddasi, 2012). The carrying capacity of data is referring to the number of operating wavelengths. A total of 128 wavelengths are offered in DWDM services and 18 wavelengths are offered to the CWDM implementation. Thus the issues on bandwidth demand and additional functions have been resolved.

\section{MATERIALS AND METHODS}

Problem that arises later is; an effect of increasing the number of users through the random formation of new nodes within a certain area topology. If the original topology used a mesh network node connection pattern, it does not give much trouble as new nodes that have 
been formed are connected randomly on the nearby nodes, but it is different if the original nodes used are in the ring structure. The randomly formation of new nodes at the outer ring spiral structure requires a restructuring on the network which has been used (Comellas et al. 2004; Gubbins 2003; Mutafungwa 2001). Then there is the phenomenon of migration topology particularly from ring topology to mesh topology. Since the nodes that used in a ring topology cannot function in the structure of mesh topology, so installation of new nodes need to be performed. Apart from that, the cultivation of fiber optic cable is also needed. Indirectly, it will increase the cost of reinstallation and a waste of time. In addition, the occurrence of interference in data transmission for a long period also will happen. These will complicate the situation if the restructuring process involves on the optical management and administration (OA and $\mathrm{M}$ ). Many entrepreneurs are looking for a node which was developed through a combination of OADM and OXC to ease the process of migration as shown in (Gubbins 2003). To overcome this problem, a design of node that is able to function in both types of topologies as well as offer general security for any defect that occurs in both topologies have to be developed. So far, there is no node that combines optical linear protection scheme, the ring protection and multiplex protection on a system has been developed (Ab-Rahman, 2008). Fig. 1 shows an overview of the restructuring process that has been carried out in original ring network as a result of randomly growth nodes which is out on that ring. This restructuring process requires the operational cost, financial and labor that is too high in demand, as well as involving the restructuring process on optical management and administration (OA and $\mathrm{M})$. The emergence of OXADM as a universal device is the solution to the problems that arising from the migration topology, where it is the latest issue in the world of optical communications. Many studies have been conducted to investigate the feasibility of this device in experimental optical network (Ab-Rahman et al. 2010), simulation (Ab-Rahman 2008) and analytical modeling. These include a reviewing on existing limitations of OXADM scaling on network (AbRahman and Shaarani, 2009a Ab-Rahman et al. 2009b), $\mathrm{An}$ analysis on ratio of signal and noise in network (AbRahman et al 2009c), the gain of most appropriate (AbRahman, 2009d) and the injection of new signals on 'Add' terminal (Ab-Rahman and Shaarani, 2009a).

Topology Migration From Ring to Mesh: Features of capability on a migration from ring to mesh topology has been on primary agenda today in order of classifying and determining the ability of an optical node other than network security mechanisms which offered (Comellas et al. 2004; Gubbins 2003).

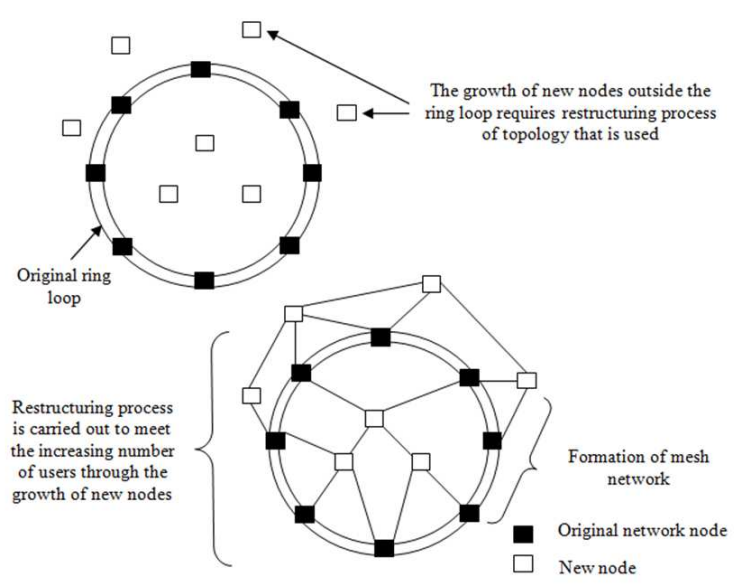

(a)
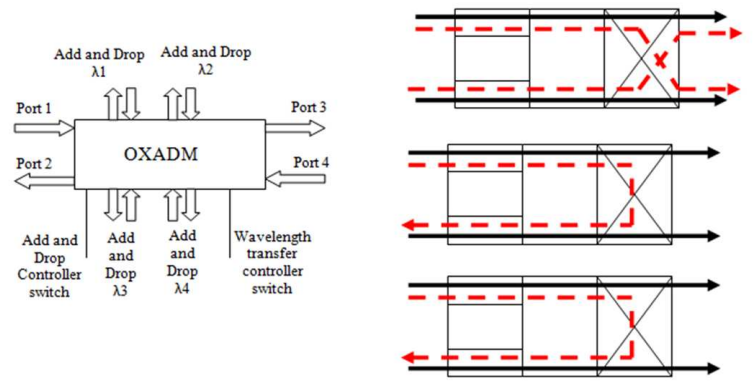

(b)

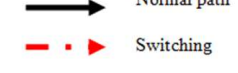

Fig. 1: (a) Current issues that involve the restructuring of original topology network due to the increasing in number of users through the growth of new nodes. (b) OXADM that used as an optical node and the mechanism of its directing path.

Usually this feature is only available on optical nodes based on optical cross talk such as OXC, OCCS and AWGM (Tsushima et al. 1998). On the other hand, this feature is not available at any optical node that based on OADM device such as TRN and this is a weakness that available on this type of nodes (Eldada and Nunen 2000). However, the migration phenomenon from ring to mesh topology is not critical in today's communication networks. Thus, the network security is on top of current issue in order to determine the type of node that can be used and these migration characteristics have become the designer and operator's second choice. However, these characteristics are expected to become an important element on optical node in the future if the expansion of network is apply to existing networks and a migration process needs to 
be done. These optical nodes do not have to be converted to mesh topology nodes (such as OXC, OXN, OCCS etc) and this can reduce the re-installation costs of nodes and in the process of restructuring network, the freezing networks can be avoided.

For a futuristic optical node, this feature should be incorporated in the OXADM design. As OXADM is designed from a combination of two main device features of OADM and OXC, then it is able to migrate from a ring topology to mesh topology while maintaining its function as an optical network security systems with both linear protection mechanisms, multiplex and ring can be carried out simultaneously in an optical node (Ab-Rahman and Shaari, 2006; AbRahman and Shaari, 2007; Ab-Rahman, 2008).

OXADM configuration in topology migration: Figure 2a shows a migration from ring to mesh topology using OXADM architecture that operates with the same signal on both bases. Architecture of this OXADM migration is called as an OXADM1 configuration. The protection bandwidth of ring network ( $\lambda 3$ and $\lambda 4)$ will function as a working bandwidth for mesh network while working bandwidth for a ring network ( $\lambda 1$ and $\lambda 2)$ is also used as a working bandwidth on the mesh network. This configuration will increase the data capacity (up to two times) on data transmission in mesh network because all the channels are assigned as the data transmission. The weakness of this configuration is its multiplex protection not possible to be done and OXADM will function as OXC in mesh network. This is shown in Fig. 2b. The pattern topology of formed mesh is the configuration that has been used today. Figure 3a shows a migration topology from ring to mesh using OXADM architecture that operates with different signals at both terminals. The architecture of this OXADM migration is called as an OXADM configuration. All working bandwidth for ring network $(\lambda 1, \lambda 2, \lambda 3$ and $\lambda 4)$ will also be used as a working bandwidth in mesh network, where it illustrates in Fig. 3b. In addition, all the protection bandwidth in a ring network will remain as a protection bandwidth in mesh network. The feasibility of multiplex protection will improve the security level of ring and mesh network but the data transmission capacity will be less than the OXADM 1 configuration.

\section{RESULTS AND DISCUSSION}

Migration using OXADM 1 configuration: Figure 4 shows the migration from ring and mesh network using the configuration of OXADM 1. The operation on same wavelength for both OXADM configuration make the signal becomes more flexible to be sent to any database in the mesh structure.

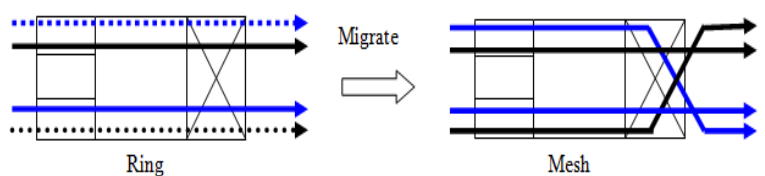

(a)

\begin{tabular}{|c|c|c|}
\hline Signal & Ring network & Mesh Network \\
\hline$\lambda 1 \mathrm{a}$ and $\lambda 2 \mathrm{a}$ & Working bandwidth & Working bandwidth \\
\hline$\lambda 3 \mathrm{~b}$ and $\lambda 4 \mathrm{~b}$ & Protection bandwidth & Working bandwidth \\
\hline$\lambda 3 \mathrm{a}$ and $\lambda 4 \mathrm{a}$ & Working bandwidth & Working bandwidth \\
\hline$\lambda 1 \mathrm{~b}$ and $\lambda 2 \mathrm{~b}$ & Protection bandwidth & Working bandwidth \\
\hline & $\because$ & \\
\hline
\end{tabular}

(b)

Fig. 2: (a) Migration topology use a configuration of OXADM and (b) Function of bandwidth for bothtopologies

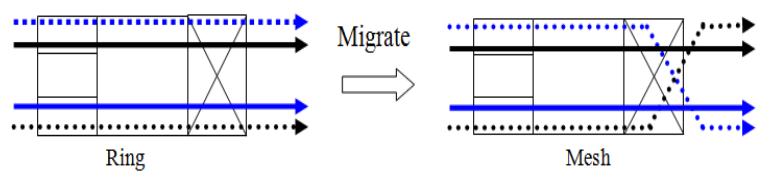

(a)

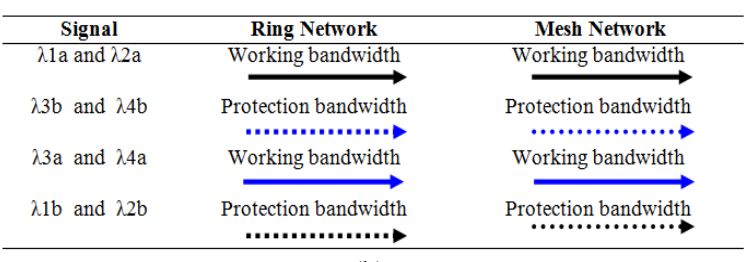

(b)

Fig. 3: (a) Migration topology use a configuration of OXADM 2 and (b) Function of bandwidth for both topologies

Table 1: Network specification for topology migration from ring to mesh by using OXADM 1 configuration

\begin{tabular}{ll}
\hline Network Specification & Value \\
\hline Node insertion dissipation & $14.8 \mathrm{~dB}$ \\
Load line & 32.3 \\
First pre-amplifier & $10 \mathrm{~dB}$ \\
Pre-amplifier & $12 \mathrm{~dB}$ \\
Post-amplifier & $21 \mathrm{~dB}$ \\
Photosensitivity & $-25 \mathrm{dBm}$ \\
Data transmission rate & $2.5 \mathrm{Gbps}$ \\
Distance between two nodes & $70 \mathrm{~km}$ \\
\hline
\end{tabular}

This simulation study is intended to obtain the output power and BER performance on each node for the topology migration process that using OXADM 1 configuration. The value of pre-amplifier and postamplifier gain for both topologies has been prescribed. A network specification for topology migration is shown in Table 1. 


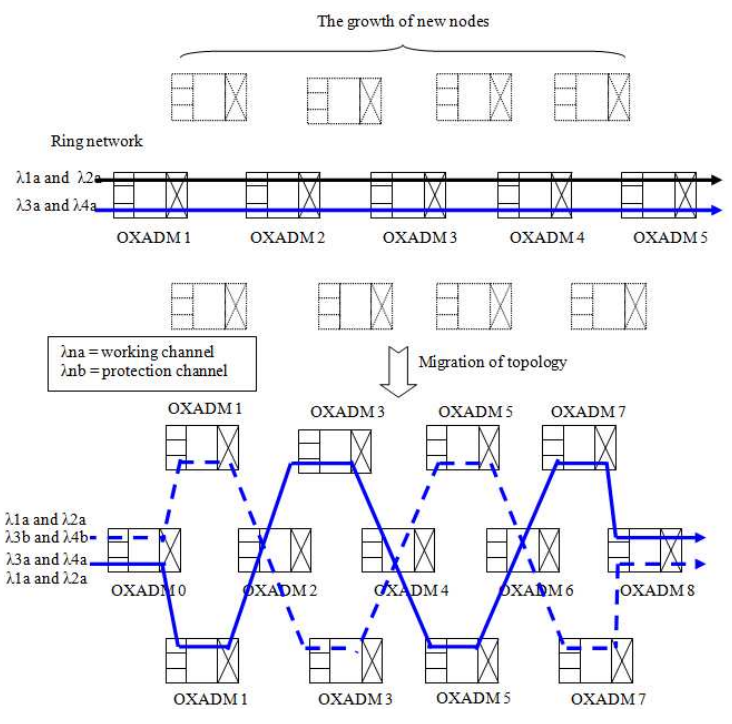

Fig. 4: Migration of topology from ring to mesh using OXADM 1 configuration. OXADM handle half of transmission capacity for ring network and using full of transmission capacity for mesh networks

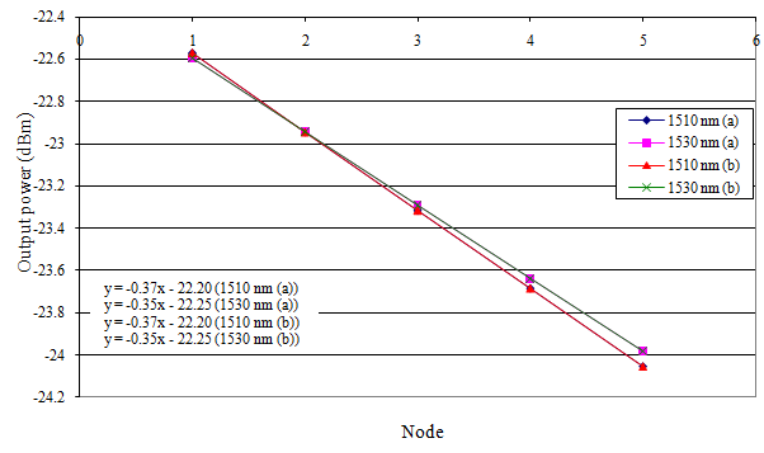

Fig. 5: Output power at each node in ring network for working channels $\lambda(a)$ and protection channel $\lambda(b)$ for a wavelength of $1510 \mathrm{~nm}$ and $1530 \mathrm{~nm}$

Figure 5 shows the output power at each node for a ring network for working channel (1510 nm (a) and 1530 $\mathrm{nm}$ (a)) and channel protection (1510 nm (b) and 1530 $\mathrm{nm}(\mathrm{b}))$. Since the total gain of $33 \mathrm{~dB}$ is used and this is the optimum value of load line value of $32.8 \mathrm{~dB}$, it produces a satisfactory BER profile (BER $<1 \times 10^{-9}$ ) as shown in Fig. 6. Output power for the same signal on both bases gives the same reading. Figure 7 and 8 respectively show the output power and BER performance for a ring network for working channel (1550 nm (a) and $1570 \mathrm{~nm}$ (a)) and channel protection (1550 nm (b) and $1570 \mathrm{~nm}$ (b)). Output power for all nodes in the dynamic range ( $25 \mathrm{~dB}$ power budget) gives the BER less than 1x10-9. This protection channel will be used in the protection mechanism when it is activated.

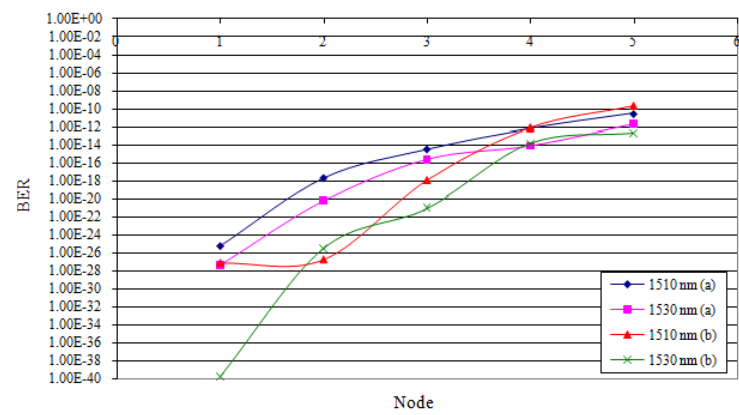

Fig. 6: BER performance at each node in ring network for working channels $\lambda$ (a) and protection channel $\lambda(b)$ for a wavelength of $1510 \mathrm{~nm}$ and $1530 \mathrm{~nm}$

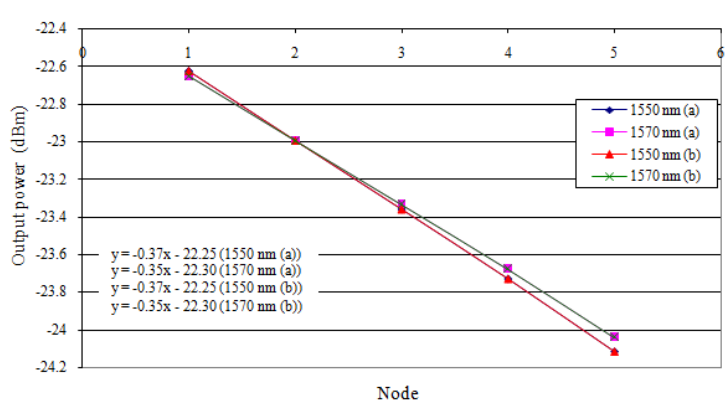

Fig. 7: Output power at each node in ring network for working channels $\lambda$ (a) and protection channel $\lambda$ (b) for a wavelength of $1550 \mathrm{~nm}$ and $1570 \mathrm{~nm}$.

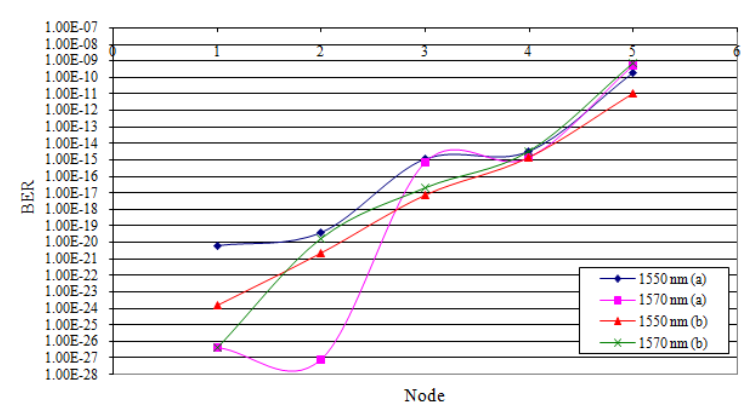

Fig. 8: BER performance at each node in ring network for working channels $\lambda(a)$ and protection channel $\lambda(b)$ for a wavelength of $1550 \mathrm{~nm}$ and $1570 \mathrm{~nm}$

Figure 9 shows the output power at each node in mesh network for a working wavelength after the migration process is conducted. All same signals on both base gives the same output power. Each node provides output power at a dynamic range, except on the $9^{\text {th }}$ node. However, it can be restored by increasing the amplifier gain of $1 \mathrm{~dB}$ at any of the amplifiers that have been used. Fig. 10 shows the BER performance for each node in mesh network after the migration is conducted. 


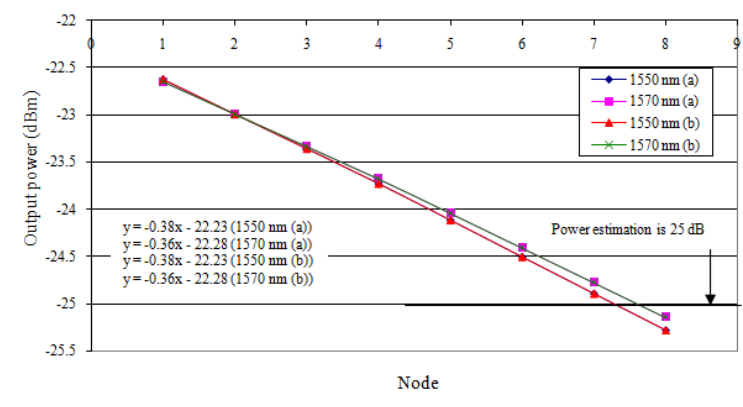

Fig. 9: Output power of each node for mesh network on working channel

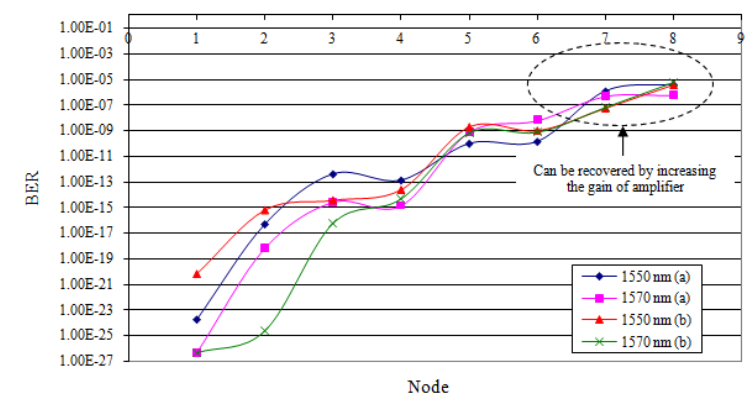

Fig. 10: BER of each node for mesh network on working channel

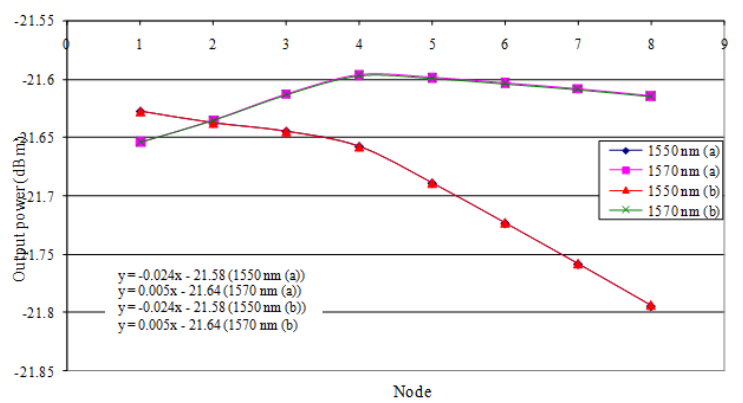

Fig. 11: The increasing of preamplifier gain at $0.36 \mathrm{~dB}$ will keep the constant value of output power at each node in mesh network (working channel)

Based on Fig. 5, 7 and 9, the slope of graph gives the value of $\mathrm{m}$ by 0.35 . This shows that there is a remaining dissipation at each node that is not compensated by gain of amplifier which used. It proved by Eq. 1 .

The value of amplifier that still does not compensated is:

$=1 \mathrm{~dB}$-[total gain of amplifier $(\mathrm{dB})-$ load line, $(\mathrm{dB})]$

$=1 \mathrm{~dB}-[33 \mathrm{~dB}-32.3 \mathrm{~dB}]$

$=0.3 \mathrm{~dB}$

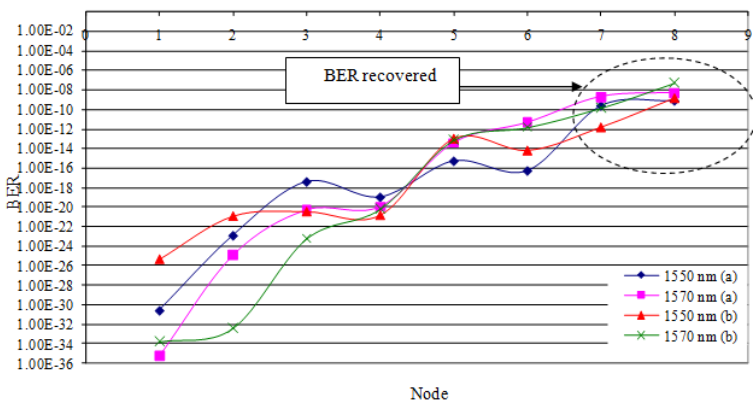

Fig. 12: The increasing of preamplifier gain at $0.36 \mathrm{~dB}$ will recover BER performance at node 8 and 9 in mesh network (working channel)

This value is equal to the slope of graph as found in the previous study. Therefore, the following simulation study will increase the gain of the preamplifier at 0.36 $\mathrm{dB}$ (equal to the gain of amplifier which suggested by Eq. 2.

Figure 11 shows the new output power at each node after the preamplifier gain is increased as high as $0.36 \mathrm{~dB}$. The slope of graph gives the reading, $\mathrm{m}=$ $0.0242(1550 \mathrm{~nm})$ and $0.0052(1570 \mathrm{~nm})$; shows the power level at each node is at same value (about -21.5 $\mathrm{dB})$. First and second pre-amplifier gains are respectively at $11 \mathrm{~dB}$ and $12.36 \mathrm{~dB}$ while the post amplifier gain is at $21 \mathrm{~dB}$. The use of amplifier gain which satisfies the Eq. 2 has recovered BER performance on each node particularly at node 7 and node 8 in mesh network. This is shown in Fig. 12. The conclusion from this simulation study shows a migration can be done properly by using an OXADM configuration with no change in specifications networks, especially on the amplifier gain which is used. The value of amplifier gain that required for both ring and mesh network is referring to Eq. 2.

A migration using OXADM 2 Configuration: Figure 13 shows the process of migration from ring to mesh topology network using OXADM 2 configuration as a distribution node. Signal path in metropolitan mesh network shown in Fig. 14 and it will be used as a reference in the following simulation studies. Network specifications that shown in Table 2 and 3 are for distance at two nodes; which are $70 \mathrm{~km}$ and $80 \mathrm{~km}$ respectively. The results are shown from Fig. 15 until Fig. 20. This simulation study aimed at studying the effects of changes at a distance between two nodes against the output power and BER performance on mesh network after it has been migrated from a ring network. In addition, the value of actual amplifier gain that required for mesh network will also be expressed and determined. 


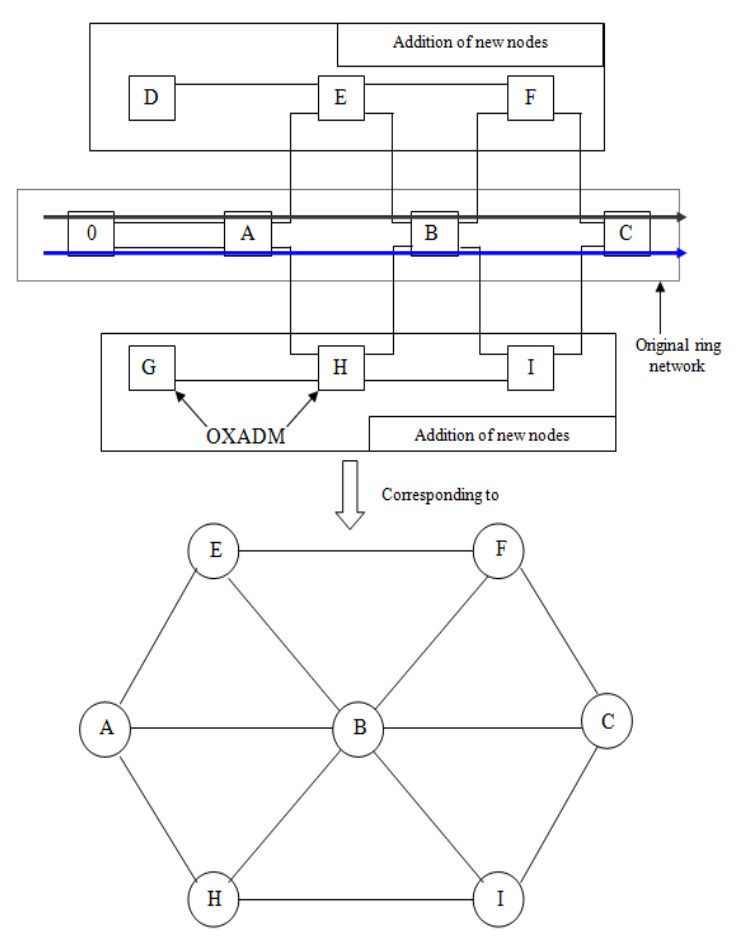

Fig. 13: Migration of topology from ring to mesh network using OXADM2 configuration. OXADM used only half transmission capacity on ring network and mesh network

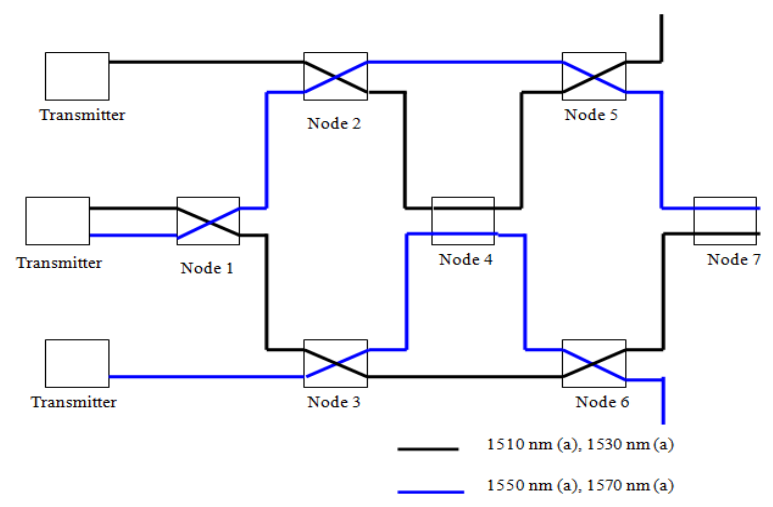

Fig. 14: Signal propagation paths in mesh network using configuration OXADM 2 as a distribution node. The next simulation study will refer to these signal paths

Figure 15 shows the output power at each node in mesh network with the distance between two nodes is $70 \mathrm{~km}$. Because the design of nodes structure in mesh network is in random position, thus the received power at each node is higher than nodes in the ring network that has been connected by a series. The output power at each node is also stable and gives favorable readings in BER performance (the maximum BER in this case is $9 \times 10^{-9}$ ).

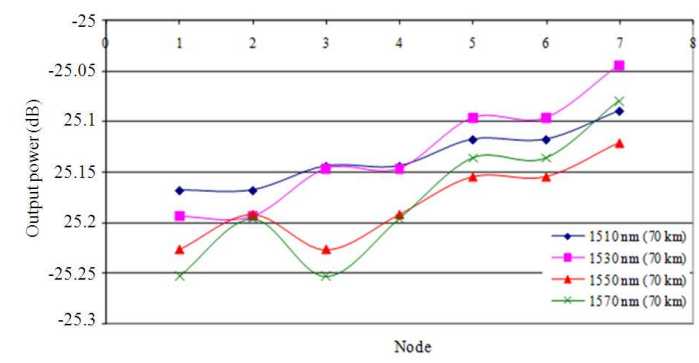

Fig. 15: Output power for each node in metropolitan mesh network; where the distance between two nodes is $70 \mathrm{~km}$

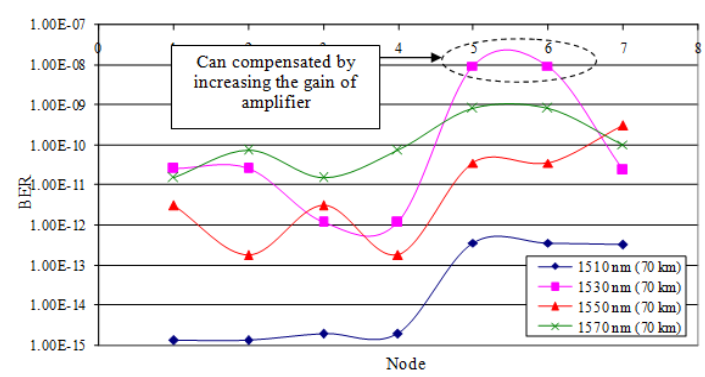

Fig. 16: BER performance for each node in metropolitan mesh network; where the distance between two nodes is $70 \mathrm{~km}$

Table 2: Mesh network specifications used in simulation studies using Optisystem for the distance between two nodes

\begin{tabular}{ll}
\hline Specification & Value \\
\hline $\begin{array}{l}\text { Distance between two nodes } \\
\text { The gain of first preamplifier } \\
\text { (from transmitter) }\end{array}$ & $70 \mathrm{~km}$ \\
$\begin{array}{l}\text { The gain of post-amplifier } \\
\text { The gain of second }\end{array}$ & $3 \mathrm{~dB}$ \\
preamplifier and so on & $22 \mathrm{~dB}$ \\
$\begin{array}{l}\text { Data transmission rate } \\
\text { Photosensitivity }\end{array}$ & $7 \mathrm{~dB}$ \\
& OC- 48 \\
& $-25 \mathrm{dBm}$ at \\
& $1530 \mathrm{~nm}(2.5 \mathrm{GHz})$ \\
\hline
\end{tabular}

The value of total gain is equal to the load line where the first preamplifier gain is recorded at $3 \mathrm{~dB}$. As a result, BER performance for each node in this mesh network is shown in Fig. 16.

If the distance between two nodes is extended up to $80 \mathrm{~km}$ by using similar amplifier gain value, then the value of output power at each node starts to decline and its BER performance began to lag. This is because the load line is larger than the gain which is used. The effect of increasing distance between these two nodes against the output power and BER performance at each node are shown in Fig. 17 and 18. It shows that, there is a decrease in output power at each node with a rate of $1.2377 \mathrm{dBm} / \mathrm{dB}$. A sharp decline in BER values has been occurred for each node and it gives the maximum reading when arriving at fifth node. 


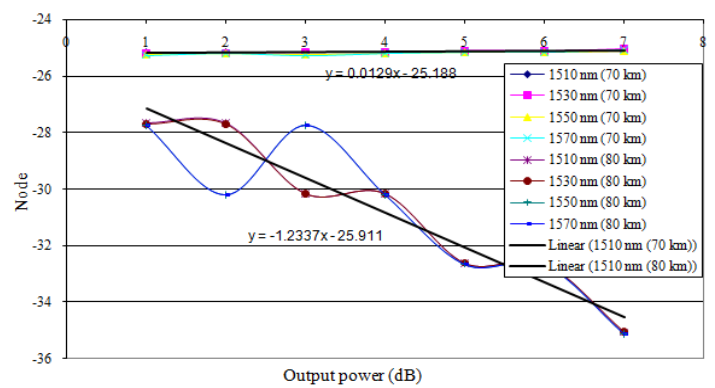

Fig. 17: Comparison of output power at distance between two nodes $(70 \mathrm{~km}$ and $80 \mathrm{~km})$; where the value of gain amplifier has been prescribed. The value of amplifier gain is equal to load line for a distance between two nodes is $70 \mathrm{~km}$.

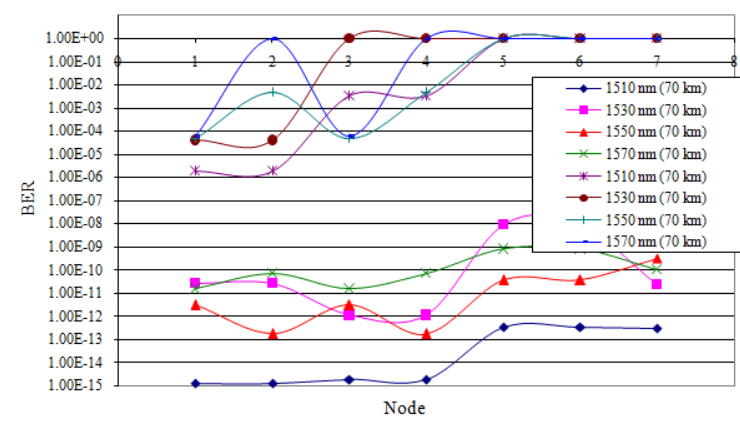

Fig. 18: Comparison of output power at distance between two nodes $(70 \mathrm{~km}$ and $80 \mathrm{~km})$; where the value of gain amplifier has been prescribed. The value of amplifier gain is equal to load line for a distance between two nodes is $70 \mathrm{~km}$

To compensate the decline on this BER performance, the gain amplifier at each node must be improved. The effect of increasing value on gain amplifier; in which from $29 \mathrm{~dB}$ (the load of distance between two nodes is $70 \mathrm{~km}$ ) to $32 \mathrm{~dB}$ (the load of distance between two nodes is 80 $\mathrm{km}$ ) can be seen in Fig. 19 and 20. Noted that; the output power is restored and it is in a stable condition and also provide a good BER performance measurement. So, it can be concluded that the minimum gain required in metropolitan mesh network are as follows:

The minimum gain required (mesh metropolitan), $d B$ $=$ Load line $(\mathrm{dB})+$ operational dissipation $(\mathrm{dB})$

where operational dissipation value is taken as $1 \mathrm{~dB}$

The minimum gain value required in mesh network is equal to the minimum gain that required in the ring network shows that; if migration process occurs and the distance between two nodes are same, then the value of gain that connects those two nodes can be maintained without any change.

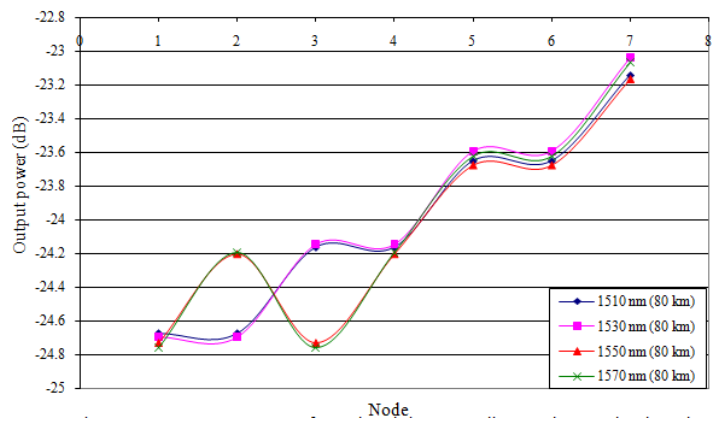

Fig. 19: Output power for each node in metropolitan mesh network; where the distance between two nodes is $80 \mathrm{~km}$.

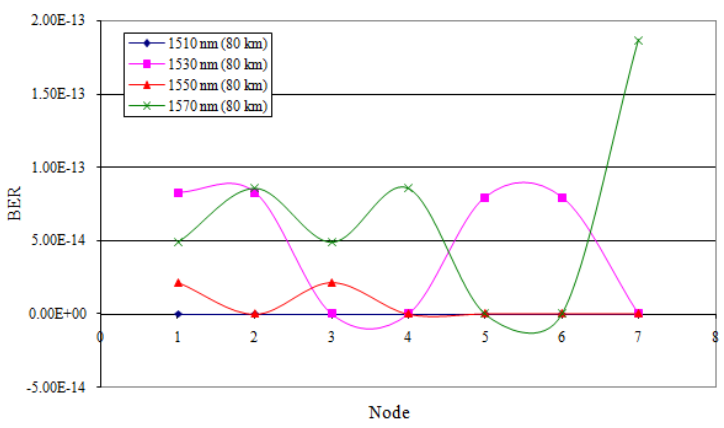

Fig. 20: BER performance for each node in metropolitan mesh network; where the distance between two nodes is $80 \mathrm{~km}$

Table 3: Specifications of mesh network that used in simulation studies using Optisystem software at distance between two nodes is $80 \mathrm{~km}$.

\begin{tabular}{ll}
\hline Specifications & Value \\
\hline $\begin{array}{l}\text { Distance between two nodes } \\
\text { First pre-amplifier gain } \\
\text { (from transmitter) }\end{array}$ & $80 \mathrm{~km}$ \\
$\begin{array}{l}\text { Post-amplifier gain } \\
\text { Second pre-amplifier }\end{array}$ & $6 \mathrm{~dB}$ \\
gain and subsequently & $25 \mathrm{~dB}$ \\
Photosensitivity & $7 \mathrm{~dB}$ \\
& $-25 \mathrm{dBm}$ at \\
& $1530 \mathrm{~nm}(2.5 \mathrm{GHz})$ \\
\hline
\end{tabular}

This simulation study shows that; migration can be done using the configuration OXADM 2. Any dissipation due to the increase in distance between two nodes can be compensated with the gain of the amplifier. Amplifier gain that needed for mesh network is based on Eq. 2 and equal to Eq. 1 for a ring network. Therefore, it can be concluded that between these two networks will require the same amplifier gain and this facilitates the migration process to be done. This has also been demonstrated in the characterization incurred using the configuration of OXADM 1 migration at Fig. 5 until Fig. 12. 


\section{CONCLUSION}

OXADM was designed to operate in two different topologies which are ring and mesh. The scenario today requires optical nodes that can function in both circumstances because the migration can be done when there are new growth nodes outside of the ring and it will needs a new topology. Hence, this study reports two configurations of migration that has been done by OXADM node. With OXADM, the restructuring network which optical node conversion and EDFA gain modification do not have to be done because OXADM can maintain a small dissipation (at $6 \mathrm{~dB}$ ) and it has an ability to function as a cross-talk. Output power performance and bit error rate (BER) can be used as a performance measurement and that evidence made the feasibility of this proposal.

\section{ACKNOWLEDGEMENT}

This study was conducted at Institute of Micro and Nano Electronic Engineering (IMEN), UKM and measurement equipment that is Pseudo Random Bit Rate Generator has been borrowed from Optical Communications Research Laboratory, Faculty of Engineering, UPM. OXADM device has been filed for a patent application on February 10, 2009; in which the reference number is PI20090491.

\section{REFERENCES}

Ab-Rahman, M.S. and M.F.A.S Shaarani, 2009a. Determination of the suitable injection signal and internal gain for optical cross add and drop multiplexer in survivable optical ring network. Australian J. Basic Applied Sci., 3: 1177-1184.

Ab-Rahman, M.S and S. Shaari, 2006. Mesh upgraded ring in metropolitan network using OXADM. Proceedings of the 5th International Conference on Optical Communications and Networks and the 2nd International Symposium on Advances and Trends in Fiber Optics and Applications, (ICOCN/ATFO' 06), China, pp: 225-227.

Ab-Rahman, M.S, 2008. Optical network restoration and migration using OXADM. The 10th International Conference on Advanced Communication and Technology (Korea). Feb. 1720, IEEE Xplore Press, Gangwon-Do, pp: 21552160. DOI: 10.1109/ICACT.2008.4494216
Ab-Rahman, M.S and S. Shaari, 2007. Survivable mesh upgraded ring in metropolitan network. J. Optical Commun., 28: 206-211.

Ab-Rahman, M.S., M.K.A.M. Nor and M.N. Dollah. 2009b. Analytical Analysis of Limited Power Penalty on Optical Cross Add and Drop Multiplexer (OXADM) - with OXC Comparison. J. Optical Commun., 30: 179-185.

Ab-Rahman, M.S., S.M. Mustaza and M.S.D. Zan and A. Baharudin 2010. OXADM Dalam Sistem Keselamatan Rangkaian Cincin Metropolitan. J. Teknologi, Universiti Teknologi Malaysia, 52: 149-161.

Ab-Rahman, M.S, T.S. Ling, A.T.S. Ee, L. Zaharah and F. Jaafar. 2009c. OSNR analysis on Optical Cross Add and Drop Multiplexer (OXADM) in Ring Metropolitan (CWDM) network: the analytical approach. J. Optical Commun., 30: 195-199.

Ab-Rahman, M.S., 2009d. Gain optimization improves BER performance in metropolitan ring network Simulation approach. Australian J. Basic Applied Sci., 3: 1725-173.

Ab-Rahman, M.S and M. Moghaddasi, 2012. A Comparison between electrical and optical chromatic dispersion compensation in wavelength divison multiplexing network regarding to electrical pulse shapes. J. Comput. Sci., 8: 76-83. DOI: $10.3844 /$ jcssp.2012.76.83

Comellas, J., C. Linares, J. Ramon, J. Conesa, G. Junyent, 2004. Using nodes with shared wavelength converters in optical networks. Proceedings of the 6th International Conference, Jul. 4-8, IEEE Xplore Press, 1: 43-46. DOI: 10.1109/ICTON.2004.1360242

Gubbins, E., 2003. Sprint seeks mesh migration for its domestic backbone.

Mutafungwa, E., 2001. Circulating loop simulations for transmission performance comparison of various node architectures. J. Optics: Pure Applied Phys. 3: 255-261. DOI:10.1088/1464-4258/3/4/305

Tsushima, H., S. Hanatani, T. Kanetake, J.A. Fee, S.K. Liu, 1998. Optical cross-connect system for survivable optical layer networks. Hitachi Rev., 47: 85-90. 